Volume 3, Issue 2, pages 161-170

\title{
Study of Nickel Extraction Process from Spent Catalysts with Hydrochloric Acid Solution: Effect of Temperature and Kinetics Study
}

Kevin Cleary Wanta ${ }^{1,{ }^{*}}$, Ivanna Crecentia Narulita Simanungkalit ${ }^{1}$, Elsha Pamida Bahri ${ }^{1}$, Ratna Frida Susanti ${ }^{1}$, Gelar Panji Gemilar ${ }^{2}$, Widi Astuti ${ }^{3}$, Himawan Tri Bayu Murti Petrus ${ }^{4}$

${ }^{1}$ Department of Chemical Engineering, Parahyangan Catholic University, Jl. Ciumbuleuit 94, Bandung 40141, Indonesia

${ }^{2}$ PT Petrokimia Gresik, Jl. Jenderal Ahmad Yani, Gresik 61119, Indonesia

${ }^{3}$ Research Unit for Mineral Technology, Indonesian Institute of Sciences

(LIPI), Jl. Ir. Sutami Km. 15, Tanjung Bintang 35361, Indonesia

${ }^{4}$ Department of Chemical Engineering, Universitas Gadjah Mada, Jl. Grafika 2, Kampus UGM, Yogyakarta, 55281, Indonesia

*Corresponding Author: kcwanta@unpar.ac.id

(Received 20-08-2021; Revised 19-09-2021; Accepted 20-09-2021)

\begin{abstract}
As one of the hazardous and toxic solid wastes, spent catalysts need to be treated before the waste is discharged into the environment. One of the substances that need to be removed from the spent catalysts is the heavy metal ions and/or compounds contained therein. The method that can be applied is the extraction method using an acid solvent. In this study, the extraction process was carried out on spent catalysts samples from PT. Petrokimia Gresik. The focus of the study is on nickel extraction by varying the temperature in the range of $30-85{ }^{\circ} \mathrm{C}$. A $1 \mathrm{M}$ hydrochloric acid $(\mathrm{HCl})$ solution was used as a solvent while the extraction process was 120 minutes. The experimental results show that the maximum nickel recovery of $14.70 \%$
\end{abstract}




\section{International Journal of Applied Sciences and Smart Technologies}

Volume 3, Issue 2, pages 161-170

p-ISSN 2655-8564, e-ISSN 2685-9432

can be achieved at a temperature of $85{ }^{\circ} \mathrm{C}$. Kinetic studies were carried out using two kinetic models. The results of both models evaluation on the research data show that the lump model gives better results than the shrinking core model. The average error percentage of the lump model is smaller than the shrinking core model. It indicates that the extraction process was controlled by the diffusion step through the ash layer in the solid and chemical reactions simultaneously.

Keywords: Extraction, lump model, nickel, shrinking core model

\section{Introduction}

Various chemical industries, such as the oil, fertilizer, and petrochemical industries require catalysts to increase the rate of chemical reactions. The catalysts used can be solid catalysts containing different metal contents, such as nickel $(\mathrm{Ni})$, iron $(\mathrm{Fe})$, cobalt (Co), vanadium (V), molybdenum (Mo), and various other heavy metals [1]. The use of catalysts in the long term will make the catalyst saturated and no longer adequate for use. Thus, these catalysts will be replaced and disposed of as a used catalyst or what is usually called spent catalysts. Spent catalysts can not be disposed of directly into the environment because these catalysts are classified as hazardous solid waste. Therefore, this waste needs to be treated first with the aim of taking hazardous compounds, such as heavy metals contained in it.

One of the spent catalysts solid waste treatment that can be done is extracting ions or compounds contained in the catalysts. This method is usually referred to as the leaching method. This method is a commonly used method and has been done by several researchers before. This extraction process requires a solvent to react and dissolve the metal ions and/or compounds. The solvents usually used are acidic solvents, both strong acids and weak acids [1], [2], [3], [4].

In this study, the extraction process was carried out using a hydrochloric acid solution. Furthermore, this research also studies parameters that have a significant impact on the extraction process, such as temperature. Temperature is an important parameter in the extraction process because temperature affects the rate of molecular 


\section{International Journal of Applied Sciences and Smart Technologies}

Volume 3, Issue 2, pages 161-170

p-ISSN 2655-8564, e-ISSN 2685-9432

diffusion and the rate of chemical reactions. Furthermore, by studying the effect of temperature in the extraction process, the kinetic study of this process can be investigated by utilizing the existing kinetic models, such as the shrinking core model and the lump model. By studying the kinetics of the extraction process, a proper extractor can be designed. A proper extractor design must follow the applicable mechanism of the extraction process. Thus, the results of this study are expected to provide the appropriate information for the extractor design process.

\section{Research Methodology}

Materials. The main raw material of this research is the spent catalyst from PT. Petrokimia Gresik. These catalysts have a nickel content of $16.7 \% \mathrm{wt}$, where the largest nickel phase in these catalysts is nickel elements (metals) and nickel oxide compounds (NiO). In addition, another main material used is a $1 \mathrm{M}$ hydrochloric acid $(\mathrm{HCl})$ solution. This $\mathrm{HCl}$ solution acts as a solvent in this extraction process.

Equipment. The main equipment used for the extraction process is a series of equipment consisting of a three-neck flask (as an extractor), stirrer and motor, condenser, water bath and thermostat (to maintain a constant operating temperature), and a thermometer. As a sample analysis instrument, the instrument used is Atomic Absorption Spectroscopy (AAS).

Research procedure. $180 \mathrm{~mL}$ of $1 \mathrm{M}$ hydrochloric acid solution was put into a threeneck flask. After the equipments were assembled, the solution was heated to the desired temperature. In this study, the operating temperature was varied at 30,60 , and $85^{\circ} \mathrm{C}$. After the temperature was reached, 36 grams of the spent catalyst solids ( $<74$ microns) were put into the extractor. This solids intake will be counted as $t=0$. The extraction process lasted for 120 minutes where during the operation time, the sampling was carried out periodically at 5, 10, 15, 30, 60, and 120 minutes. The samples that had been taken would be separated first between the solid and the liquid phase. This separation process was carried out using a centrifuge which was operated at 1,000 rpm for 10 


\section{International Journal of Applied Sciences and Smart Technologies}

Volume 3, Issue 2, pages 161-170

p-ISSN 2655-8564, e-ISSN 2685-9432

minutes. The supernatant formed was then analyzed for the nickel content in the solution using Atomic Absorption Spectroscopy (AAS) instruments.

Data analysis. The data obtained from the analysis using the AAS instrument is processed to obtain the result in the form of nickel recovery percentage where the equation used to calculate the value is:

$$
x=\frac{C_{N i}}{C_{N i, t o t}} \times 100 \%
$$

where $\mathrm{x}$ is the percentage of nickel recovery, $\mathrm{CNi}$ is the concentration of nickel extracted during the extraction process in ppm, $\mathrm{CNi}$, tot is the total nickel concentration extracted from raw materials in ppm.

Furthermore, the nickel recovery data will be used to study the kinetics of the extraction process. There are two kinetic models applied in this study, namely the shrinking core model and the lump model. For the shrinking core model, the equations used are [5], [6], [7]:

Diffusion in liquid film layer controlling $\quad: x^{\prime}=k_{f} \cdot t$

Diffusion in ash layer controlling $\quad: 1-3\left(1-x^{\prime}\right)^{0,67}+2\left(1-x^{\prime}\right)=k_{d} \cdot t$

Chemical reaction controlling

$$
\text { : } 1-\left(1-x^{\prime}\right)^{0,33}=k r . t
$$

where $\mathrm{x}^{\prime}$ is the nickel recovery fraction, $\mathrm{kf}, \mathrm{kd}$, and $\mathrm{kr}$ are the rate constants for the extraction process, and $\mathrm{t}$ is the operating time. For the lump model, the equations used are [8]:

$$
\frac{d x}{d t}=\left[\alpha \cdot \frac{1}{\left(1-x^{\prime}\right)}+\beta \cdot \frac{\left\{\left(1-x^{\prime}\right)^{1 / 3}-1\right\}}{\left(1-x^{\prime}\right)^{1 / 3}}\right]^{-1}
$$

where $\alpha$ is a constant related to the rate at the chemical reaction step while $\beta$ is a constant related to the rate at the diffusion step in the ash layer.

Determination of the suitable mathematical model is done by calculating the percentage error of research data and simulation data. The equation used is as follows:

$$
\% E=\left|\frac{\left(x_{\text {data }}^{\prime}-x_{\text {sim }}^{\prime}\right)}{x_{\text {data }}^{\prime}}\right| \times 100 \%
$$




\section{International Journal of Applied Sciences and Smart Technologies}

Volume 3, Issue 2, pages 161-170

p-ISSN 2655-8564, e-ISSN 2685-9432

where $\% \mathrm{E}$ is the percentage of error, $x^{\prime}{ }_{\text {data }}$ is the percentage of nickel recovery from experimental data, and $x^{\prime}{ }_{\text {sim }}$ is the percentage of nickel recovery from the simulation results of mathematical models.

\section{Results and Discussion}

Effect of temperature on nickel recovery. Temperature is a very important parameter and has a significant influence on determining the rate of the extraction process. In this study, the temperature used is in the range of $30-85{ }^{\circ} \mathrm{C}$. The experimental results are presented in Figure 1.

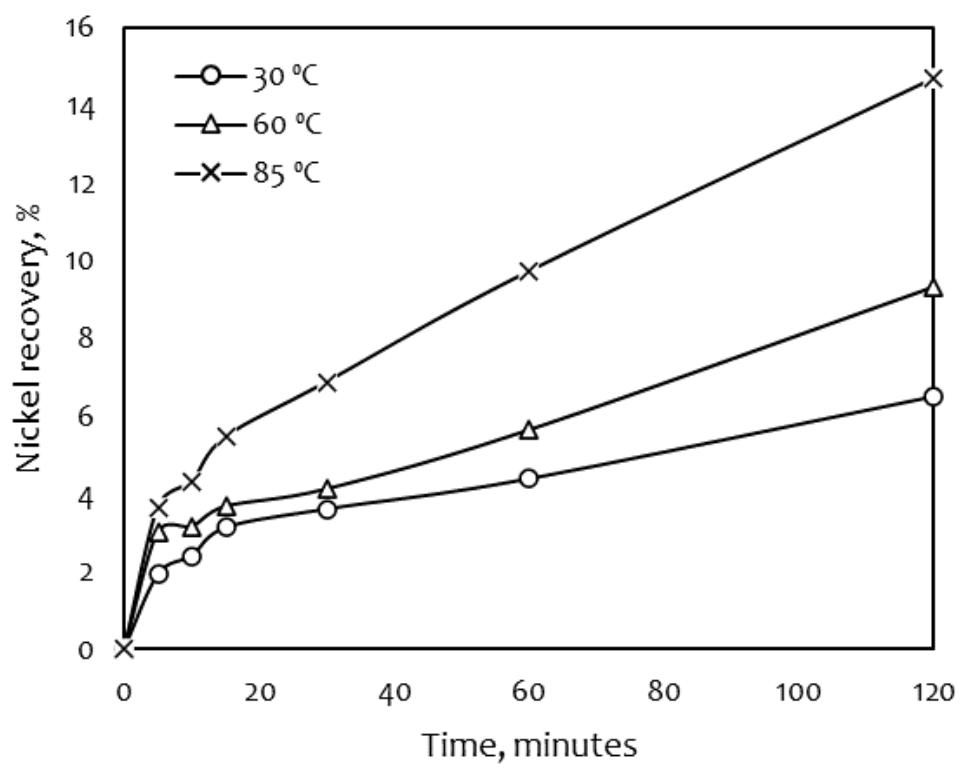

Figure 1. Effect of temperature on nickel recovery

Figure 1 shows that the higher the temperature used, the more nickel can be obtained. In this study, the highest nickel recovery was obtained during the process at a temperature of $85{ }^{\circ} \mathrm{C}$ for 120 minutes, where the percentage of nickel recovery was $14.70 \%$. In general, the nickel recovery that occurs during the process can reach 1.44 (for a temperature of $60{ }^{\circ} \mathrm{C}$ ) and 2.25 times (for a temperature of $85{ }^{\circ} \mathrm{C}$ ) compared to nickel recovery at a temperature of $30{ }^{\circ} \mathrm{C}$. This phenomenon can occur because an 


\section{International Journal of Applied Sciences and Smart Technologies}

Volume 3, Issue 2, pages 161-170

p-ISSN 2655-8564, e-ISSN 2685-9432

increase in temperature will enhance the kinetic energy of each molecule in the system. Consequently, each molecule will collide more often so that chemical reactions will also take place more quickly. In addition, an increase in temperature will also enhance the rate of diffusion, both molecular diffusion in the liquid film layer and diffusion in the ash layer in the solid.

Kinetics study using the shrinking core model. The first kinetic model to be evaluated against the experimental data above is the shrinking core model. This model is the model most widely used by previous researchers in the hydrometallurgy or metal extraction process. The evaluation of this model is carried out using mathematical equations (2-4) and the evaluation results obtained are presented in Figure 2.

a.

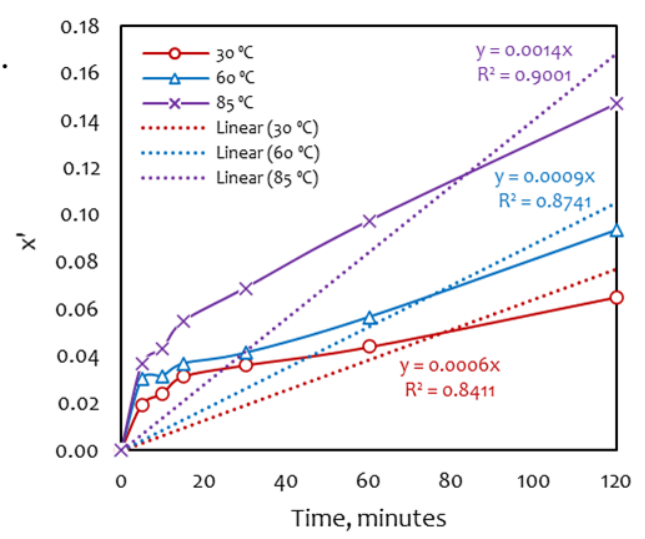

b.

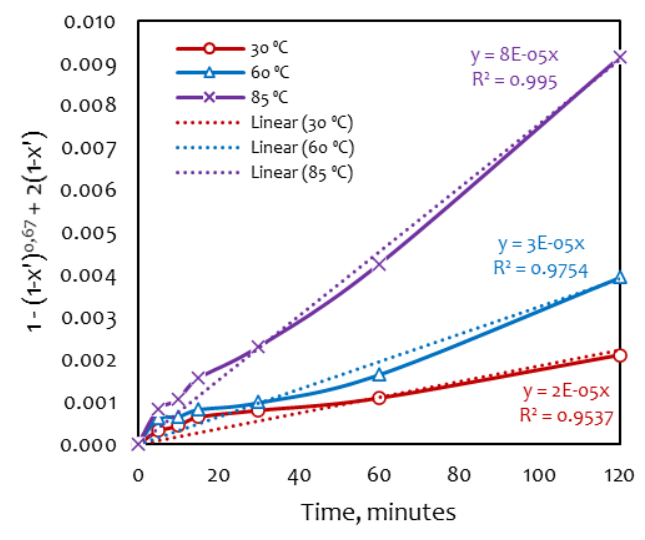

c.

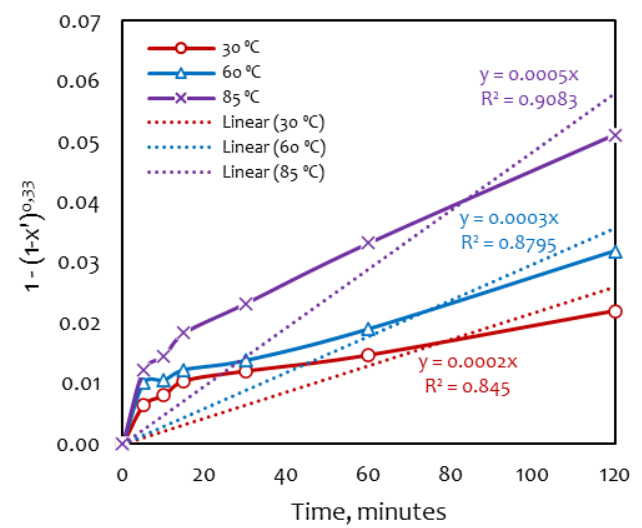

Figure 2. Simulation results of the shrinking core model when (a) diffusion in the liquid film layer controlling; (b) diffusion in the ash layer controlling; (c) chemical reactions controlling 


\section{International Journal of Applied Sciences and Smart Technologies}

Volume 3, Issue 2, pages 161-170

p-ISSN 2655-8564, e-ISSN 2685-9432

Figure 2 shows the simulation results of the experimental data. The simulation results show that the shrinking core model in which the diffusion step in the ash layer controlling is the best model to illustrate the overall mechanism during the extraction

process. This can be concluded because the $\mathrm{R}^{2}$ value obtained in this model is better than the other two models (diffusion step in the film layer and chemical reactions that control the process). A good $R^{2}$ value is an $R^{2}$ value that is close to 1 .

The evaluation results obtained indicate that the diffusion step through the ash layer in the solid is the step with the slowest rate. In solids, there are pathways used for each molecule (both reactant and product molecules) to diffuse. This pathway has a small size so that the reactant molecules that diffuse from the surface of the liquid to the unreacted surface in the solid will interfere with each other with the product molecules that diffuse from the surface that has reacted in the solid to the liquid body. It causes diffusion through the ash layer in the solid to be the step that controls the extraction process. Thus, the total rate of nickel extraction from the spent catalyst is determined by the rate of diffusion in the solid (the slowest rate).

Another parameter commonly used to evaluate the kinetics of a process is the activation energy. Activation energy is the minimum energy required for a reaction to occur. The value of this parameter can be found using the Arrhenius equation as follows [9]:

$$
\begin{aligned}
& \mathrm{k}=\mathrm{A} \exp \left(-\frac{\mathrm{Ea}}{\mathrm{RT}}\right) \\
& \ln \mathrm{k}=\ln \mathrm{A}-\frac{\mathrm{Ea}}{\mathrm{RT}}
\end{aligned}
$$

where $\mathrm{A}$ is the collision frequency, $\mathrm{E}_{\mathrm{a}}$ is the activation energy, $\mathrm{R}$ is the gas constant, and $\mathrm{T}$ is the absolute temperature. In this extraction process, the value of the collision frequency (A) obtained is 0.1384 , while the activation energy value is $22.65 \mathrm{~kJ} / \mathrm{mol}$. According to Havlík, if the activation energy value is in the range of $20-35 \mathrm{~kJ} / \mathrm{mol}$, the extraction process is controlled by the diffusion and chemical reactions simultaneously [10]. Therefore, this kinetic study will be continued by using the lump model, which combines the two stages to prepare the mathematical model. 


\section{International Journal of Applied Sciences and Smart Technologies}

Volume 3, Issue 2, pages 161-170

p-ISSN 2655-8564, e-ISSN 2685-9432

Kinetics study using the lump model. One of the weaknesses of the shrinking core model is that mathematical problem compiled in the model only assume one step that controls the extraction process; other steps are ignored because those steps are considered to have a very fast rate. In fact, in the solid-liquid extraction process, there are five steps involved in the system. For some cases, the use of assumptions as mentioned above does not represent the actual mechanism that occurs during the extraction process. As a result, the designed extractor will not be suitable for this process. Therefore, in this study, to complete the kinetic study, the lump kinetic model is evaluated against the experimental data where the equation used for the simulation process follows equation (5). The simulation results of the lump model are then compared with the evaluation results of the shrinking core model, where the diffusion step in the ash layer controls the extraction process. The comparison of the two kinetic models is presented in Table 1.

Table 1. Comparison of the simulation results of the shrinking core model (diffusion step in the ash layer) with the lump model

\begin{tabular}{|c|c|c|c|c|c|c|c|c|c|c|c|c|c|c|c|}
\hline \multirow{2}{*}{$\begin{array}{l}\text { Time, } \\
\text { minutes }\end{array}$} & \multicolumn{3}{|c|}{$\begin{array}{l}\text { Nickel Recovery - } \\
\text { Experimental, \% }\end{array}$} & \multicolumn{3}{|c|}{$\begin{array}{l}\text { Nickel Recovery - } \\
\text { SCM*, \% }\end{array}$} & \multicolumn{3}{|c|}{$\begin{array}{l}\text { Nickel Recovery - } \\
\text { Lump Model, \% }\end{array}$} & \multicolumn{3}{|c|}{ Error - SCM ${ }^{*}, \%$} & \multicolumn{3}{|c|}{ Error - Lump, \% } \\
\hline & $30^{\circ} \mathrm{C}$ & $60^{\circ} \mathrm{C}$ & $85^{\circ} \mathrm{C}$ & $30^{\circ} \mathrm{C}$ & $60^{\circ} \mathrm{C}$ & $85^{\circ} \mathrm{C}$ & $30^{\circ} \mathrm{C}$ & $60^{\circ} \mathrm{C}$ & $85^{\circ} \mathrm{C}$ & $30^{\circ} \mathrm{C}$ & $60^{\circ} \mathrm{C}$ & $85^{\circ} \mathrm{C}$ & $30^{\circ} \mathrm{C}$ & $60^{\circ} \mathrm{C}$ & $85^{\circ} \mathrm{C}$ \\
\hline 0 & 0.00 & 0.00 & 0.00 & 0.00 & 0.00 & 0.00 & 0.00 & 0.00 & 0.00 & 0.00 & 0.00 & 0.00 & 0.00 & 0.00 & 0.00 \\
\hline 5 & 1.92 & 3.02 & 3.66 & 0.74 & 1.17 & 2.35 & 1.41 & 1.89 & 3.04 & 61.35 & 61.28 & 35.67 & 26.56 & 37.42 & 16.94 \\
\hline 10 & 2.41 & 3.16 & 4.32 & 1.29 & 1.96 & 3.49 & 1.99 & 2.67 & 4.28 & 46.36 & 37.90 & 19.23 & 17.43 & 15.51 & 0.93 \\
\hline 15 & 3.13 & 3.68 & 5.46 & 1.75 & 2.60 & 4.51 & 2.43 & 3.27 & 5.23 & 44.07 & 29.27 & 17.44 & 22.36 & 11.14 & 4.21 \\
\hline 30 & 3.61 & 4.13 & 6.88 & 2.84 & 4.09 & 6.83 & 3.43 & 4.60 & 7.34 & 21.32 & 0.91 & 0.78 & 4.99 & 11.38 & 6.69 \\
\hline 60 & 4.39 & 5.65 & 9.73 & 4.44 & 6.24 & 10.10 & 4.83 & 6.46 & 10.27 & 1.08 & 10.36 & 3.80 & 10.02 & 14.34 & 5.55 \\
\hline 120 & 6.51 & 9.34 & 14.70 & 6.73 & 9.27 & 14.67 & 6.78 & 9.05 & 14.30 & 3.33 & 0.76 & 0.23 & 4.15 & 3.10 & 2.72 \\
\hline \multicolumn{10}{|c|}{ The average error percentage per temperature: } & 25.36 & 20.07 & 11.02 & 12.22 & 13.27 & 5.29 \\
\hline \multicolumn{10}{|c|}{ The average error percentage per kinetics model: } & \multicolumn{3}{|c|}{18.82} & \multicolumn{3}{|c|}{10.26} \\
\hline
\end{tabular}

*SCM: the shrinking core model with a diffusion step in the ash layer controls the process.

Based on Table 1, the lump kinetics model provides better evaluation results than the shrinking core model. This can be concluded from the average error percentage for both 


\section{International Journal of Applied Sciences and Smart Technologies}

Volume 3, Issue 2, pages 161-170

p-ISSN 2655-8564, e-ISSN 2685-9432

models, namely $10.26 \%$ for the lump model and $18.82 \%$ for the shrinking core model. These results further corroborate the previous information that the spent catalyst extraction process using $1 \mathrm{M}$ hydrochloric acid solution is controlled by the diffusion step through the ash layer and chemical reactions simultaneously.

\section{Conclusion}

Based on the experimental dan simulation results, temperature significantly affects the nickel extraction process from spent catalysts with hydrochloric acid as solvent. At a temperature of $85 \mathrm{oC}$, the nickel recovery can reach $14.70 \%$ after the process lasts for 120 minutes. From the research data, the mechanism of the extraction process was studied and it was found that the rate of the extraction process was determined by the diffusion step through the ash layer in the solid and the chemical reaction step. Both of these stages occur simultaneously. The use of the lump model proves the conclusions obtained. Based on the average error percentage, the model gives a smaller error value than the shrinking core model. The average error percentage for the lump model is $10.26 \%$.

\section{Acknowledgements}

The authors thank the Institute for Research and Community Service of Parahyangan Catholic University, which has supported this research financially. In addition, the authors also thank PT. Petrokimia Gresik, which has provided the main raw materials for this research.

\section{References}

[1] M. Marafi dan A. Stanislaus, "Waste Catalyst Utilization: Extraction of Valuable Metals from Spent Hydroprocessing Catalysts by Ultrasonic-Assisted Leaching with Acids.” Industrial \& Engineering Chemistry Research, 50, 9495-9501, 2011.

[2] P.K. Parhi, K.H. Park, G. Senanayake, "A kinetic study on hydrochloric acid leaching of nickel from Ni-A12O3 spent catalyst." Journal of Industrial and Engineering Chemistry, 19, 589-594, 2013. 


\section{International Journal of Applied Sciences and Smart Technologies}

Volume 3, Issue 2, pages 161-170

p-ISSN 2655-8564, e-ISSN 2685-9432

[3] J. Ramos-Cano, G. González-Zamarripa, F.E. Carrillo-Pedroza, M. de J.SoriaAguilar, A. Hurtado-Marcías, A. Cano-Vielma, "Kinetics and statistical analysis of nickel leaching from spent catalyst in nitric acid solution." International Journal of Mineral Processing, 148, 41-47, 2016.

[4] W. Mulak, B. Miazga, A. Szymczycha, "Kinetics of nickel leaching from spent catalyst in sulphuric acid solution.” Int. J. Miner. Process, 77, 231-235 2005.

[5] O. Levenspiel, Chemical Reaction Engineering. 3rd Edition, New York: John Wiley \& Sons, Inc., 1999.

[6] O.S. Ayanda, F.A. Adekola, A.A. Baba, O.S. Fatoki, B.J. Ximba, "Comparative Study of the Kinetics of Dissolution of Laterite in some Acidic Media." Journal of Minerals \& Materials Characterization \& Engineering, 10 (15), 1457-1472, 2011.

[7] K.C. Wanta, F.H. Tanujaya, R.F. Susanti, H.T.B.M. Petrus, I. Perdana, W. Astuti, "Studi Kinetika Proses Atmospheric Pressure Acid Leaching Bijih Laterit Limonit Menggunakan Larutan Asam Nitrat Konsentrasi Rendah.” Jurnal Rekayasa Proses 12 (2), 77-84, 2018.

[8] K.C. Wanta., W. Astuti, I. Perdana, H.T.B.M. Petrus, "Kinetic Study in Atmospheric Pressure Organic Acid Leaching: Shrinking Core Model versus Lump Model." Minerals, 10, 1-10, 2020.

[9] H.S. Fogler, Element of Chemical Reaction Engineering. 4th Edition, New Jersey: Prentice Education, Inc., 2006.

[10] T. Havlík, Hydrometallurgy. Cambridge: Woodhead Publishing Limited, 2006. 